\title{
LA INFLUENCIA DE PAULO FREIRE EN LA CONFORMACIÓN DE LA EDUCACIÓN POPULAR AUTÓNOMA EN LA PROVINCIA DE QUEBEC
}

\begin{abstract}
Resumen
Este artículo tiene como objetivo analizar la influencia que tuvo Paulo Freire en el discurso y en la práctica de la Educación popular, especialmente en las experiencias de la Educación Popular Autónoma, EPA, tal como fue definida en la provincia francoparlante de Quebec Canadá. Con este propósito, se resumirá la historia de la aparición del discurso de la educación popular en Quebec y se intentará una definición de la Educación Popular Autónoma, EPA, destacando la influencia que Freire tuvo, y aún tiene, en su definición y su praxis por parte de los grupos que la han adoptado como referente.

Palabras clave: Educación popular, Paulo Freire, movimientos Sociales, comunidad, Quebec.

\section{A INFLUÊNCIA DE PAULO FREIRE NA CONFORMAÇÃO DA EDUCAÇÃO POPULAR AUTÔNOMA NA PROVÍNCIA DE QUÉBEC}

\section{Resumo \\ O artigo visa analisar a influência que teve Paulo Freire no discurso e na prática da Educação popular, especialmente nas experiências da Educação Popular Autónoma (EPA) tal como foi definida na província francoparlante de Québec (Canadá). Com este propósito resumir-se-á a história do aparecimento do discurso da educação popular em Québec, e tentar-se-á uma definição da Educação popular autónoma (EPA) destacando a influência que Freire teve, e ainda tem, em sua definição e sua praxis por parte dos grupos que a adoptaram como referente. \\ Palavras chaves: Educação popular, Paulo Freire, movimentos sociais, comunidade, Québec \\ THE INFLUENCE OF PAULO FREIRE IN THE DEFINITION OF AUTONOMOUS POPULAR EDUCATION IN THE PROVINCE OF QUEBEC}

\begin{abstract}
The goal of this article is to analyze Paulo Freire's influence in the discourse and practice of popular education, especially in the experiences of Autonomous Popular Education (APE or EPA in French) as it was defined in the francophone province of Quebec (Canada). With this purpose in mind we will look how the discourse of popular education appeared in Quebec, and we will try to define the concept of Autonomous Popular Education, taking into account Freire's influence had, and still has, in its definition and practice by the groups who have it as a guideline.
\end{abstract}

Key word: Popular education, Paulo Freire, social movements, community, Québec.

* Université de Montréal (Québec). El autor ha participado en movimientos sociales de Quebec durante los últimos diez años y ha trabajado para varios grupos comunitarios de Educación Popular Autónoma, EPA.

Correo electrónico: philippe.viens@umontreal.ca

Articulo recibido el 16 de abril de 2009 y aprobado el 28 de mayo de 2009 


\section{ORÍGENES DE LA EDUCACIÓN POPULAR AUTÓNOMA EN LA PROVINCIA DE QUEBEC}

Bernard Vallée (1991), del Instituto Canadiense de Educación de Adultos, ICEA, identifica cuatro experiencias de educación de adultos y de sus protagonistas, que fueron precursoras de la educación popular en Quebec:

1. La del militante socialista Albert SaintMartin, fundador del Partido Obrero de Montreal y del Partido Socialista, organizador de la primera manifestación del 1 de mayo. Vallée dice (1991) que "como educador popular, [...] su contribución ha sido la más importante: fundada en 1925 por Saint-Martin y sus amigos, la Universidad Obrera tuvo una influencia importante en los sectores sociales obreros y populares". Se ofrecían conferencias sobre "temas de cultura general, entonces inaccesibles a los sectores populares (historia, literatura, economía, política, geografía, astronomía, etc.) y tenían lugar debates ideológicos alrededor de los derechos de las mujeres, de la religión, de cuestiones internacionales o de la actualidad política" (Vallée, 1991), en los cuales participaban cientos de personas. También se daban clases de arte oratorio y de teatro, y se organizó una biblioteca popular donde se prestaban libros. Las actividades de la Universidad Obrera y las ideas socialistas y anticlericales de Albert Saint-Martin van a atraer los ataques de la Iglesia, de la prensa, del gobierno y de organizaciones fascistas. En 1935, una ley especial del gobierno provincial obliga a la Universidad Obrera cerrar sus puertas.

2. La de la fundadora de la Alianza Canadiense por el Derecho al Voto de las Mujeres (1927), Idola Saint-Jean. Por medio de la Alianza, Idola ofrecía talleres y conferencias sobre temas de política y de economía, inauguró una biblioteca móvil y prestaba servicios jurídicos para las obreras. Así mismo, organizó cada año una gran marcha hacia el Parlamento por el derecho al voto en la provincia, el cual lograron en 1940.
3. El trabajo de Léa Roback quien luchará toda su vida por los derechos de los sectores populares. En 1936, se hace responsable de la sección educativa de un sindicato de trabajadoras de la ropa. Roback dirá: "Para que el sindicato sea realmente un herramienta de defensa, las obreras deben aprender a protegerse con el conocimiento de qué es el trabajo [...]" (Vallée, 1991). Ella trabajará, hasta 1952, en la formación de delegadas, en la organización de huelgas, fundará una librería y organizará clases de alfabetización, de francés, de inglés, de danza, de artesanía, etc., para las trabajadoras que nunca tuvieron la oportunidad de instruirse.

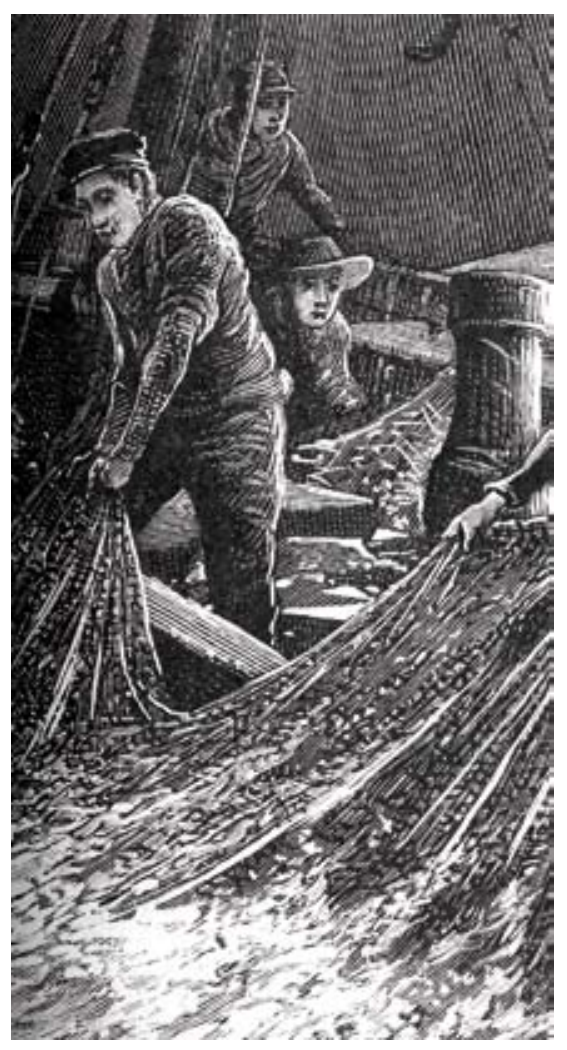

4. Fundado en 1931, el movimiento de las Juventudes Obreras Católicas, JOC, que surgió para contrarrestar la influencia de los socialistas en los sectores obreros, tenía como propósito enfrentar los problemas de los sectores populares. "El movimiento de la Joc es importante por la filosofía de la acción inculcada a sus militantes [...]. Basada sobre el procedimiento del ver-juzgar-actuar, esta filosofía se concretaba mediante una pedagogía de concienciación, la cual ha marcado toda una generación". En la provincia, donde la gran mayoría de la población era católica, la Joc se volvió un importante lugar de formación para muchos obreros y obreras, y al final de los años cuarenta tenía cinco mil militantes y muchos otros miles de simpatizantes.

Estas son, brevemente, las primeras experiencias de educación de adultos claramente visibles y diferenciables en la provincia de Quebec. Posteriomente en la década de los sesenta, hubo una acelerada transformación social, económica, política y religiosa de la sociedad quebequense, llamada la Revolución Tranquila. Dicha transformación se sucede a partir de la modernización del Estado iniciada por las políticas keynesianas del Partido Liberal de Quebec (de-confesionalización y ampliación de la educación, salud pública gratuita y universal, nacionalización de sectores de la economía, etc.) y de un crecimiento rápido de la economía. Hubo también un cambio en las mentalidades con el crecimiento de las ideas socialistas, del nacionalismo quebequense y del cuestionamiento al poder institucional de la Iglesia católica, por el cual "la noción de caridad da paso a la noción de justicia social y la noción de derecho reemplaza la noción de privilegio" (Mépaq, 1998, p. 10). Es así que a finales de esta década, aparecen las primeras políticas públicas de educación de adultos y de alfabetización y emergen muchas asociaciones y grupos organizados de ciudadanos.

Luego, en los años setenta, estos "grupos politizados entran en ruptura con la sociedad capitalista y se desarrollan, al mismo tiempo que buscan nuevas maneras de resolver los problemas sociales. La política se vuelve el asunto de todos" (Roy, 2005, p. 5). Surgen, además, en forma paralela, una multitud de grupos populares que crean sus propios servicios: bancos alimentarios cooperativos, clínicas médicas populares, servicios jurídicos comunitarios, centros de educación popular barriales, 
asociaciones de arrendatarios, guarderías populares, entre otros.

Así mismo, el Ministerio de Educación de Quebec empezó, desde 1972, un proceso de reconocimiento de los aportes de los grupos populares, principalmente por las presiones ejercidas por el Instituto Canadiense de Educación de Adultos, ICEA. La ICEA y las Organizaciones Voluntarias de Educación Populares, OVEP, quienes además trabajaron en la consolidación del financiamiento estatal, y en la organización de 450 OVEP en el ámbito provincial. En 1978, se adopta, en una asamblea general, los principios y la definición de la Educación Popular Autónoma, EPA, como referente de todos los grupos, además de una estructura nacional mínima. Estos grupos conformaron el Comité de Coordinación de las OVEP, que se transformaría posteriormente en el Movimiento por la Educación Popular y la Acción Comunitaria de Quebec, Mépacq, en 1981.

No obstante, se consideró en aquella época que muchos de los principios de la EPA iban "en contra de la filosofía de algunas organizaciones que se centran en el desarrollo personal y familiar" (Roy, 2005 , p.3) y por ello varios grupos se retiraron del proceso para conformar el Reagrupamiento de Organizaciones Voluntarias de Educación Popular, Rovep. Esto conllevó un reagrupamiento de las regionales de las OVEP, y la con- formación de las unidades principales del Mépacq.

Hoy en día el Mépacq está conformado por once reagrupamientos regionales y 333 grupos populares y comunitarios que tienen como referente la EPA. Los grupos que conforman la base del Mépacq son grupos de alfabetización, de ecologistas, de solidaridad internacional, de pastoral social, de jóvenes, de radios y prensas comunitarias, de inquilinos, de feministas, de defensa de los derechos sociales, de personas con discapacidades, de desempleados, de economía social, de defensa de los consumidores, de bancos alimentarios, entre otros. La función principal del Mépacq ha sido actuar sobre algunas políticas provinciales y federales nacionales, ayudar a la coordinación nacional de los grupos, preservar su autonomía y defender, ampliar y consolidar el financiamiento provincial de los grupos. Este ultimo objetivo fue, en parte, logrado con el desplazamiento de la responsabilidad de los grupos del Ministerio de Educación de Quebec hacia la Secretaría de la Acción Comunitaria Autónoma (Saca, hoy en día Sacais), creada con un impuesto del $5 \%$ a las ganancias de los casinos, para el financiamiento de los grupos populares (una idea del gobierno y no de los grupos de EPA). Por su parte, el Rovep está constituido, hoy en día, por sesenta grupos comunitarios.

\section{DEFINICIÓN DE LA EDUCACIÓN POPULAR AUTÓNOMA, EPA, EN QUEBEC}

En 1978, una asamblea provincial de las organizaciones voluntarias de educación popular adoptó la siguiente definición de la Educación Popular Autónoma, EPA:

La EPA es: el conjunto de los procesos de aprendizaje y de reflexión crítica por medio de los cuales los ciudadanos y ciudadanas realizan colectivamente acciones que requieren una toma de conciencia individual y colectiva con respecto a sus condiciones de vida y laborales, y que contemplan a corto, mediano o largo plazo, una transformación social, económica, cultural y política de su entorno (Mépacq, 1998, p. 5).

Además, el Mépacq definirá los principios fundamentales de la EPA, entre los cuales se encuentran: a) Tener como objetivo la transformación social y trabajar sobre las raíces de los problemas sociales, más bien que sobre sus efectos; b) Realizar acciones colectivas que susciten una toma de conciencia; c) Trabajar con poblaciones que no controlan o que controlan muy poco sus condiciones de vida y laborales; $y, d$ ) Hacer que el grupo tome su destino en sus manos y favorecer las iniciativas de aprendizaje de la población.

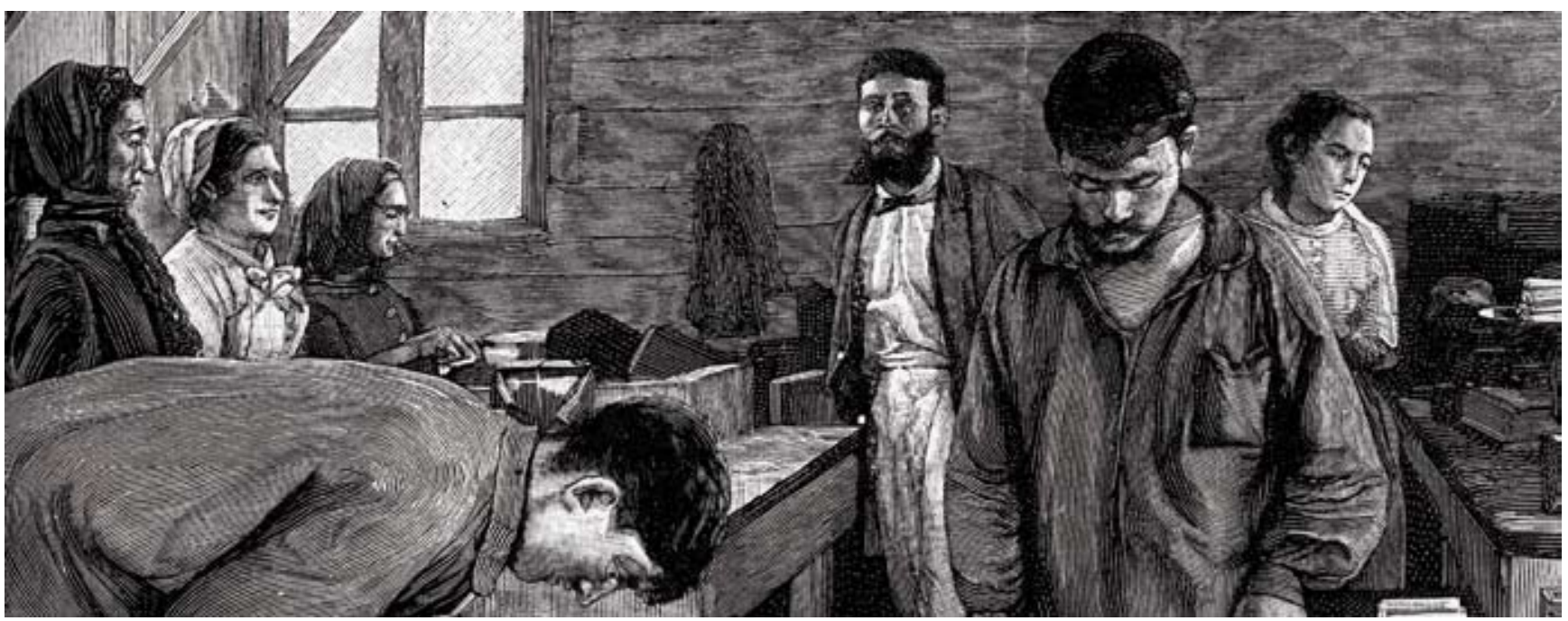


Por otro lado, el Rovep define la EPA como:

El conjunto de aprendizajes no formales con los cuales los ciudadanos toman conciencia de su situación personal, de su entorno y de sus condiciones de vida. Su planteamiento específico se distingue por la creatividad y la diversidad de los medios utilizados. La EPA ofrece a todos los adultos un conocimiento accesible y necesario para volverse un protagonista influyente al nivel individual y colectivo, con el objetivo de transformación social (Roy, 2005, p. 3).

Este definición de la educación popular se volverá el referente principal en la provincia y será practicada y aplicada por los grupos y organizaciones del Rovep y el Mépacq.

\section{LA INFLUENCIA DE FREIRE EN EL DISCURSO DE LA EDUCACIÓN POPULAR AUTÓNOMA EN QUEBEC}

Louise Doré, fundadora del Centro de Educación Popular de Pointe SaintCharles, recuerda que no se hablaba de educación popular en Quebec antes del paso de Paulo Freire, a principio de los años setenta, cuando éste ofreció una conferencia sobre la pedagogía de la concientización (Bertolino, 2007). Mientras el pensamiento de Freire se estaba difundiendo en la provincia:

Los grupos populares inician un nuevo tipo de intervención, cuestionando al mismo tiempo las prácticas educativas escolarizadas. Influenciados por la ideología "de la liberación de los pobres" [sic] en boga en toda la América Latina, la mayoría de los grupos se orientan hacia los desfavorecidos de la sociedad (Roy, 2005, p. 2).

Podemos ver así que la pedagogía de la liberación de Paulo Freire se constituyó en una influencia definitiva para la conformación del movimiento de educación popular en Quebec. Ahora bien, veamos con mayor profundidad cómo esta influencia se manifiesta en la EPA.
Alfonso Torres (2007) sintetiza los planteamientos de Freire en cuatro dimensiones: educar es conocer críticamente la realidad; educar es comprometerse con la utopía de transformar la realidad; educar es formar los sujetos de dicho cambio y educar es diálogo (Cfr. Torres, 2007, p. 30). Dimensiones que son identificables en la EPA.

Por un lado, Freire sostiene que, "lenguaje y realidad se vinculan dinámicamente" y que "la lectura del mundo precede la lectura de la palabra". La alfabetización se hace entonces con las palabras que conforman "el universo vocabular de los grupos populares, expresando su verdadero lenguaje, sus anhelos, sus inquietudes, sus reivindicaciones, sus sueños". Aprendiendo a leer y escribir, el educando aprende también a leer críticamente la realidad (Freire, 1981, p. 94). El objetivo es que los sujetos "lleguen a insertarse críticamente en la realidad" (Freire, 1995, p. 52), en contra de la falsa "realidad opresora", lo cual es el primer paso hacia la transformación de su mundo.

Esta dimensión derivada de los planteamientos de Freire, se encuentra con la definición que propone el Mépacq de la EPA. En su primera parte, la EPA llama a la existencia del "conjunto de los procesos de aprendizaje y de reflexión crítica en los ciudadanos y ciudadanas, el primer paso que lleva a una acción transformadora". Para la EPA, este aprendizaje y reflexión críticos están íntimamente ligados a las realidades de los sujetos, así que la concientización se hace por medio de las acciones colectivas de los sujetos sobre sus "condiciones de vidas y laborales". Como dice Freire, "la conciencia es 'intencionalidad' hacia el mundo" (Freire, 1970, p. 68).

Más aún, para Freire, según Torres (2007), "las prácticas educativas siempre son políticas porque involucran valores, proyectos, utopías que reproducen, legitiman, cuestionan o transforman las relaciones de poder prevalecientes en la sociedad; la educación nunca es neutral, está a favor de la dominación o de la emancipación" (pp. 31-32). La acción histórica de los sujetos consiste en transcender a las "situaciones limites" y crear el "inédito viable".

Siguiendo ese orden, La EPA define como su finalidad la "transformación social, económica, cultural y política" de la realidad del sujeto. Por su parte el Repac afirma que la EPA no es neutra ni objetiva. Ésta, toma posición por los oprimidos y los desfavorecidos. Es un método de concientización y politización". Igualmente la Mesa Redonda de Organismos Voluntarios de Educación Popular de Estrie, Trovepe, afirma que las razones de la transformación social pueden darse por o para:

El bienestar colectivo, la redistribución de las riquezas, para más justicia, para una sociedad sin sexismo ni racismo ni violencia y que no discrimina a ningún grupo social, o para permitir al más grande número de personas posible participar de las decisiones que los conciernen (Trovepe, 1992, p. 15).

Así mismo y oponiéndose a la "educación bancaria", en su documento de apropiación de los principios de la EPA, el Repac dice: "Para nosotros, la educación es trabajar juntos como creadores y creadoras de nuestra cultura, de nuestro proyecto de sociedad, y no sólo acumular conocimientos o formarse para ocupar un empleo" (Repac, 2003, p. 10). Para el Repac, la EPA "es muy diferente de la educación tradicional": "Nuestra tarea no es determinar qué debería hacer la gente ni cómo deben actuar. No somos maestros, pero debemos ser animadores y animadoras [...] al servicio del grupo" (Repac, 2003, pp. 10-11). Así, podemos ver aquí la sensibilidad de Freire según la cual la "educación debe comenzar por la superación de la contradicción educador-educando" (Freire, 1995, p. 79) y también que el "liderazgo no puede pensar sin las masas, ni para ellas, sino con ellas" (p. 170).

La EPA es dialógica. Hacer educación popular autónoma es "inventar una segunda cultura, ajena a la cultura dominante, una cultura de solidaridad, de diálogo y de lucha". En sus principios, afirma la importancia de la toma de "control del grupo (de EPA) por la población". Finalmente, la EPA es praxis, porque se 
define como aprendizaje y reflexión critica en acción y tiene como objetivo la transformación social, de acuerdo con la definición de Freire, según la cual la praxis "sólo es posible a través de la reflexión y la acción que inciden sobre las estructuras que deben transformarse" (1995, p. 162).

De esta manera, podemos concluir que la influencia de Paulo Freire ha sido determinante en la aparición y definición de la Educación Popular Autónoma en Quebec. Además, como hemos visto en los documentos de apropiación de la EPA, del Repac y de la Trovepe, creados respectivamente en 1992 y 2003 con el propósito de mejorar el entendimiento de la EPA en sus organizaciones, los planteamientos de Freire siguen vigentes en la praxis de los grupos comunitarios que la tienen como referente.

La EPA, que se conformó en esta provincia francoparlante, al extremo norte de América, es sólo una de las múltiples formas que ha tomado el pensamiento del destacado pedagogo latinoamerica- no en el mundo. En Quebec, Freire sigue inspirando a educadores y educadoras populares, desempleados, mujeres, jóvenes, militantes y otros miles de personas que participan en los cuatrocientos grupos que hacen Educación Popular Autónoma, en su transformación del mundo hacia un "inédito viable", pero muchas veces sin que se enteren del papel fundacional que ha tenido y que sigue teniendo este pedagogo en la existencia de su movimiento.

\section{BIBLIOGRAFÍA}

BERTOlino, S. (Realizador). (2007). Un plus pour tout le monde. [Documental]. Montreal: Carrefour d'éducation populaire de Pointe Saint-Charles (Office national du film).

FreIRE, P. (1970). El proceso de alfabetización política: una introducción. Ginebra: Institute of Cultural Action.

FREIRE, P. (1981). La importancia de leer y el proceso de liberación. Mexico: Siglo XXI Editores.

FreIRE, P. (1995). Pedagogía del oprimido. Madrid: Siglo XXI Editores.
MÉPACQ. (1998). Le rôle de l'éducation populaire autonome dans la transformation de la société québécoise. Montreal: Editorial Mépacq.

RePAC (2003). Faire le choix de l'éducation populaire autonome. Quebec: Repac-03-12.

Roy, M. (2005). L'éducation populaire autonome (ÉPA) au Quebec: avancées et reculs d'un mouvement populaire. Action. Montreal: Editorial Rovep.
Torres, A. (2007). La educación popular: trayectoria y actualidad. Bogotá: El Buho.

TROVEPE. (1992). L'éducation populaire autonome. Sherbrooke: Trovepe.

Vallée, B. (1991). Institut canadien d'éducation des adultes (ICÉA): Les actes du colloque national sur l'éducation populaire au Quebec. Montreal: Editorial Icea.

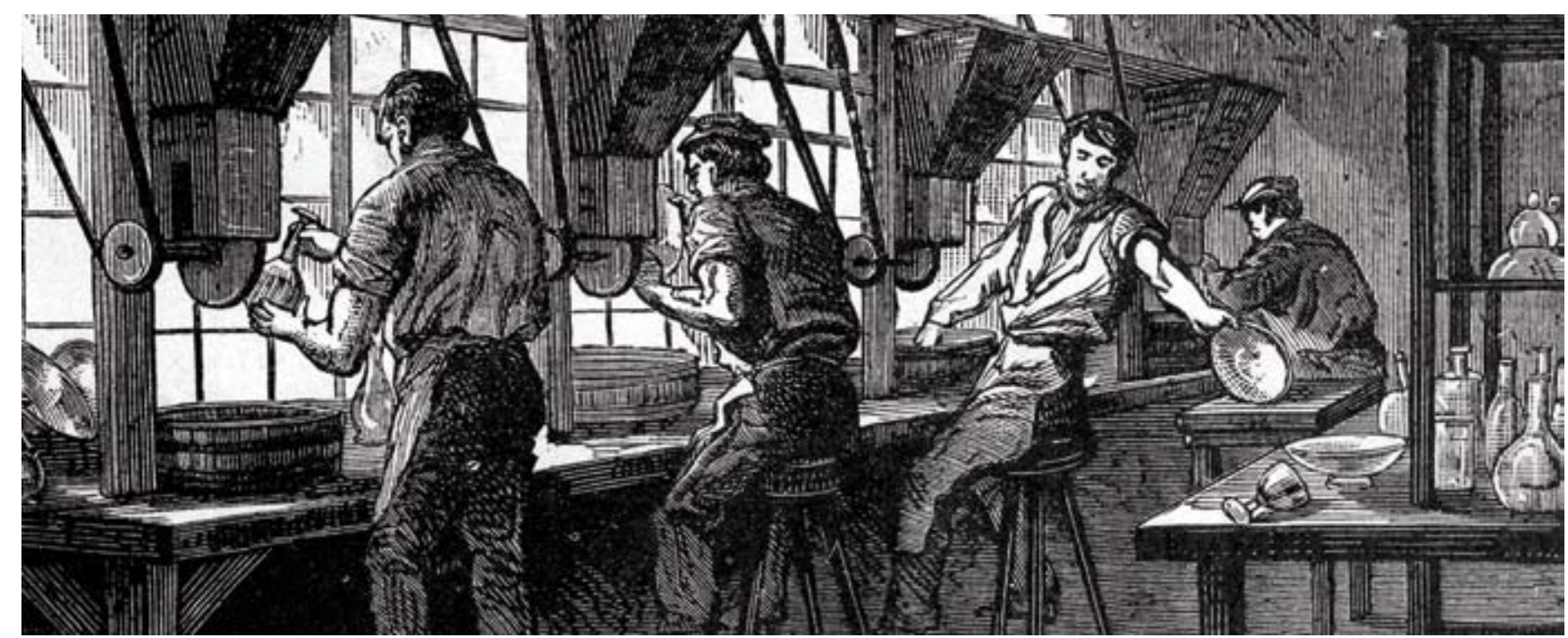




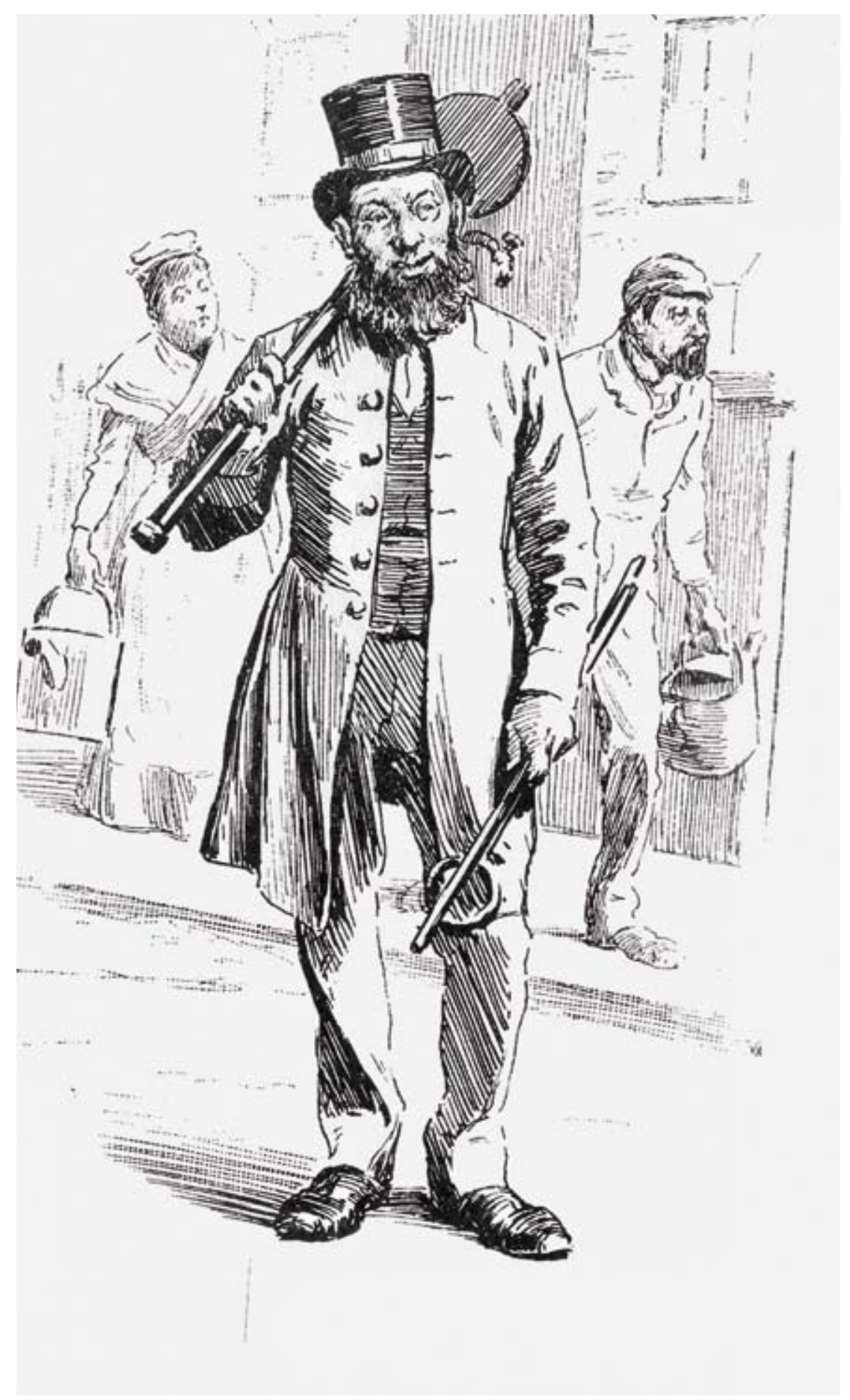

